\title{
PRELIMINARY DEVELOPMENT OF A CONCEPTUAL MODEL OF MATRIX HEAT EXCHANGER
}

\author{
Claudia Bogdan*, Catalin Brill, Oleksandr Sirosh, Mihai Vijulie, Alin Lazar \\ National Research and Development Institute for Cryogenics and Isotopic Technologies - ICSI Rm. \\ Valcea, 4 Uzinei Street, P.O. Box Raureni 7, 240050, Rm. Valcea, Romania
}

\begin{abstract}
:
While the basic principles of thermodynamics have remained the same, the necessity for heat exchangers to have good effectiveness in a small volume is constantly growing. Heat exchangers type Matrix Heat Exchanger (MHE), which can meet these requirements, does not have an optimal design variant for its use. These heat exchangers have been approached for 60 years, by many researchers, currently offering only an overview of the process. The mechanism of heat transfer in a matrix heat exchanger is complex, having three different thermal convection paths as well as thermal conduction through two different surfaces. This paper presents the simulations performed in ANSYS Workbench, combining all these heat transfer modes, for developing an optimal model of a perforated plate matrix heat exchanger, used for the pre-cooling of a hydrogen isotopes stream mixture, for purification purposes, as well as, for preparing the inlet temperature in cryogenic distillation columns of hydrogen isotopes.
\end{abstract}

\section{Article info:}

Received 26 February 2021

Received in revised form

26 February 2021

Accepted 17 March 2021

Available online 16 April 2021

Keywords:

ANSYS Workbench, Matrix Heat

Exchanger, cryogenic applications, pressure and temperature profile

How to cite: Bogdan, C., Brill, C., Sirosh, O., Vijulie, M., Lazar, A., (2021). Preliminary Development of a Conceptual Model of Matrix Heat Exchanger. Smart Energy and Sustainable Environment, 24(1), 2940, https://doi.org/10.46390/j.smensuen.24121.435.

\section{INTRODUCTION}

Perforated plate matrix heat exchangers (MHE) are smart solutions for applications that require high compactness, high effectiveness, and small dimensions (typically a few hundred millimetres). Based on the research conducted and the results published so far, this paper present the analyses performed for the influence determination of the main construction geometries of MHE's parts showing the components parts in Figure 1., aiming to obtain a preliminary configuration suitable for cryogenic applications. The dimensions, form, and arrangement of the holes of the active plates (active plates are the high conductivity parts of MHE's) and the operating regimes have been studied, using ANSYS Workbench, for different conceptual models. Based on these analyses, an experimental

*Corresponding author: Claudia Bogdan, E-mail: claudia.bogdan@icsi.ro 
model was outlined to be built and tested in the Cryogenics Laboratory, in order to accumulate experimental data that will allow finding an optimal design algorithm for this type of heat exchangers.

The simulations were performed only for the counter-current flow between hydrogen at ambient temperature and subcooled helium or hydrogen.
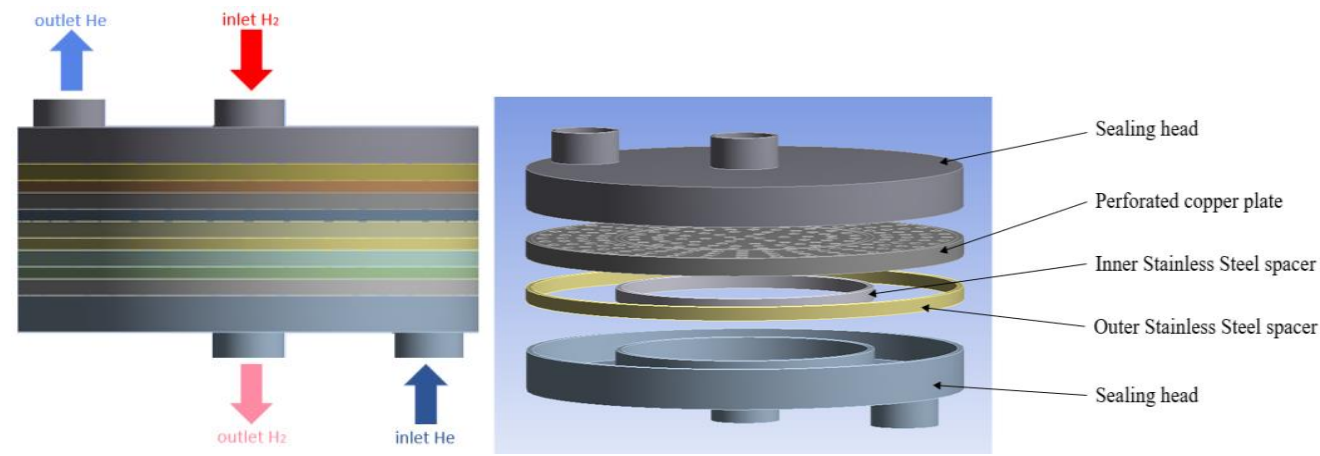

Figure 1. The components of perforated plate matrix heat exchanger

\section{MATERIALS}

Materials selected for the construction of cryogenic heat exchangers must have a high thermal conductivity to enhance the heat transfer process and also proper mechanical properties (e.g. weldability, etc.) to ensure an optimized manufacturing process. The perforated plates of a matrix heat exchanger are the "active" part, throughout the countercurrent streams flow and therefore they must have the higher thermal conductivity. The spacer rings have the function of a seal between the two flowing streams and between two successive perforated plates and for this reason, must have a low thermal conductivity. The role of the spacer rings is to minimize the longitudinal thermal conductivity that determines the reduction of the local temperature difference between the working fluids, damaging the heat transfer. In addition, both, the perforated plates and the spacer rings must have closer thermal expansion coefficients, to avoid thermo-mechanical stresses when the exchanger is cooled down. There are three methods to seal the spacer rings and the perforated plates of a matrix heat exchanger, respectively by pressing, brazing or welding. So far, three plate-spacer combinations are known, that have the above conditions: copper/stainless steel, molybdenum/alumina, and niobium/ceramic glass. However, in this paper, copper and stainless steel were studied, having in view that for the applications with equipment with no leaks, dissimilar welding between these materials is the most suitable joining method and the closest to industrial manufacturing.

\section{SHORT REVIEW}

The most efficient heat exchange can be achieved when the transfer of the heat (cold) is made at low-temperature differences, between the cold and warm streams. Apparently, this can be done if the heat exchanger can be divided into small parts with have very small differences between the inlet temperature and the outlet temperature of the cold stream and warm stream. Intuitive, matrix heat exchangers are the closest to this goal.

We present a short review of some of the interpretations and experimental date collected over the years by several authors.

The design of the matrix heat exchanger is defined by the authors (Venkatarathnam et al., 1990; Farhani et al., 2005; Ragab, 2009) by using an average heat transfer 
coefficient, $h=\Sigma h_{i} A_{i} / \Sigma A_{i}$, which is modeled by three different surfaces, such as the hollow surface of the holes and the front and rear faces of the plates, while other authors, (Dilevskaya, 1978; Ornatsakii, 1983) use the relation of the Nusselt number which depends on the geometric parameters and the Reynolds number, more precisely, on the the speed of gas flow through the holes and the diameter of the holes.

In (McMahon et al., 1950), for the calculation of the total heat transfer coefficient, $U, \frac{1}{U}=2 /\left(\eta_{\text {fin }} h\right)+b A_{1} / k_{w} A_{w}$, where $\mathrm{b}$ - width of the separator; $\mathrm{k}_{\mathrm{w}}$ - the thermal conductivity of the base material; $\mathrm{A}_{\mathrm{w}}$ - the average cross-sectional area in a set of channels; $\eta_{\text {fin }}$ - the effectiveness of the heat exchange element was considered as the heat transfer area the inner area of the holes, although for a realistic approach should be introduced the upper and lower part of the plate, as well as the area of contact with the fluid. Considering that the temperature difference between the fluid and the shape of the heat exchange element, remains constant over the entire length of the heat exchange element, (Eckert et al., 1974; Fleming, 1969; Mikulin et al., 1979) determines the efficiency of the heat exchange element thus: for rectangular plates $\eta_{\text {fin }}=\left(1+\frac{m^{2} H^{2}}{3}\right)^{-1}$ and for circular plates, $\eta_{\text {fin }}=\left(1+\frac{m^{2} r^{2}}{6}\right)^{-1},\left(\mathrm{~m}^{2}=\mathrm{hA} / \mathrm{k}_{\mathrm{p}} ; \mathrm{h}\right.$ - thermal transfer coefficient; $\mathrm{k}_{\mathrm{p}}$ - the effective thermal conductivity of the plates in the transverse direction). Mikulin attaches importance to the arrangement of holes in the plate and the thickness of the spacer, parameters that positively influence the heat transfer coefficient (Mikulin et al., 1980). Flemming's recommendation is that the spacer be thicker, and Hubbell believes that at a fixed distance, the effect of the porosity of the plate is to reduce the heat transfer coefficient (Fleming, 1969; Hubbell et al., 1986). The friction factor, strongly influenced by the thickness of the spacer and sensitive to the ratio of plate diameter to holes, than to porosity as mentioned by Hubbell et al., is determined by Mikulin et al., Fleming and Hubbell et al. does not depend on the number Reynolds fact which proves that friction due to the shape of the heat exchange element is dominant over the friction at the surface of the heat exchange element, even at small Reynolds number (Reynolds numbers are almost 200) (Mikulin et al., 1980; Fleming, 1969; Hubbell et al., 1986). In the article presented by Shevyakova et al., it is emphasized that the friction factor does not depend on the thickness of the spacer in randomly arranged plates (Shevyakova et al., 1983). The correlations given by Mikulin et al. are independent of the plate thickness and the recommendations concerning the spacer thickness to plate thickness ratio $(\mathrm{s} / \mathrm{d})$ is 0.3 for circular holes and 0.5 for straight grooves in displaced holes (Mikulin et al., 1980).

To date, the literature has provided mathematical correlations, information on flow conditions and the geometry of such equipment, but not an adequate and complete procedure for thermal analysis and design.

\section{CONCEPTUAL MODEL}

Discovery Live and ANSYS Workbench were been used to create different virtual prototypes of a matrix heat exchanger and thus to make a comprehensive analysis of these design solutions, and have a better understanding of elements that can improve performance.

\subsection{The perforations geometry effect on pressure loss}

The heat transfer of the circulating gases takes place inside of the small channels, of the order of millimetres, so that the analysis of the heat transfer in them is very important. 
The study begins by analysing the dynamic flow regime using the Discovery Live v2020R1 software from the ANSYS simulation package. The flow fields represented by the trajectory of the fluid particles have effects on the pressure drop and the heat transfer in the circular enclosures. The simulations performed focused mainly on finding a hole geometry that can accommodate a small gap for some technological parameters (temperature, pressure) of the transferred fluid, so as to avoid the occurrence of flow regimes that lead to high local heating or that make impossible the correct thermal transfer of the cold dowry in the copper plates and from them to the gas to be cooled.

In this regard, a smooth chamfer of the circular edges on the inlet side of each stream, introduces minimal friction between the gas flow and the interior walls, thus avoiding local overheating of the circulating agent and the introduction of pressure losses (Figure 2).

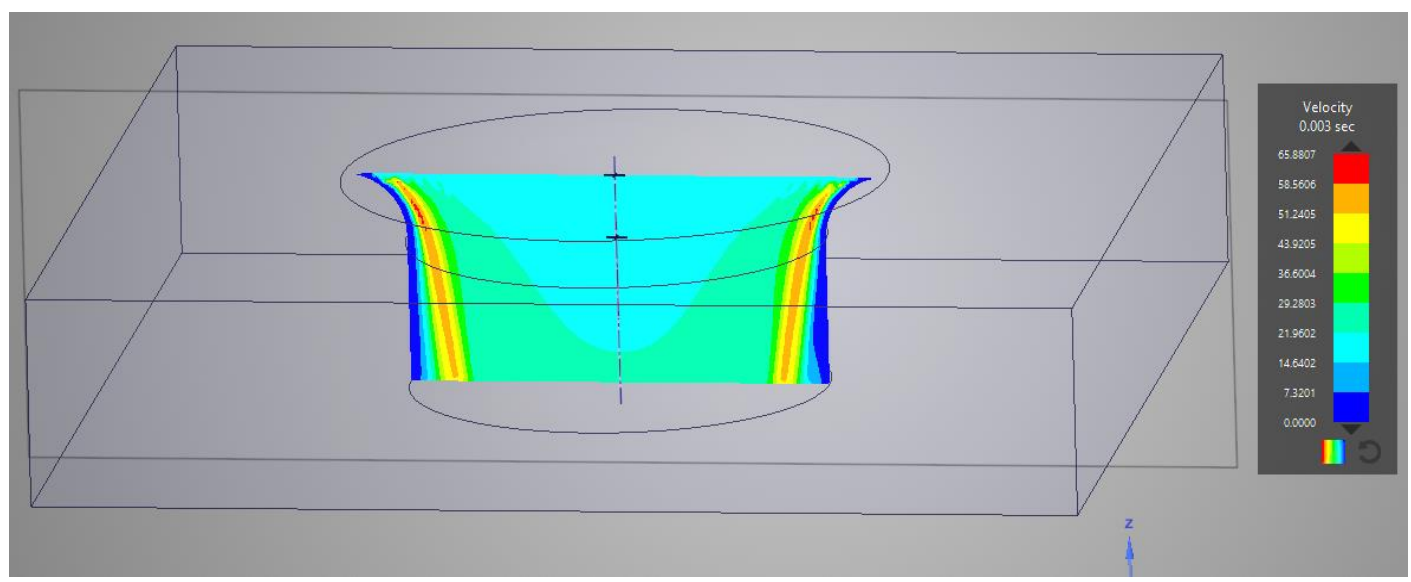

Figure 2. Velocity profile for contact side between solid and gas

\subsection{Arrangement of the two gas flows in the heat exchanger}

The geometry of the proposed matrix heat exchanger was performed within the ANSYS Workbench, using the integrated Design Modeler package. The assembly, active plate - spacer ring, axially multiplied as many times as is necessary to achieve the design parameters, to which are added two sealing heads, through which the two streams are supplied, are arranged, has a form of an elongated matrix. The arrangement of the two gas flows must be designed in such a way as to maximize the heat transfer rate in the transverse direction in the copper plate as high as possible. In this sense, two solutions were studied. For the first solution, presented in Figure 3.a, the spacer between the countercurrent gas flows, is arranged as a circular ring (1) with a hermetic band placed in the middle of the matrix (2). Into the second solution, the counter-current gas flows are separating using two concentric rings $(3,4)$ of different diameters (Figure 3.b). For the first solution were studied two arrangements of the holes from the active plate, respectively the arrangement in the square and in the triangle. 

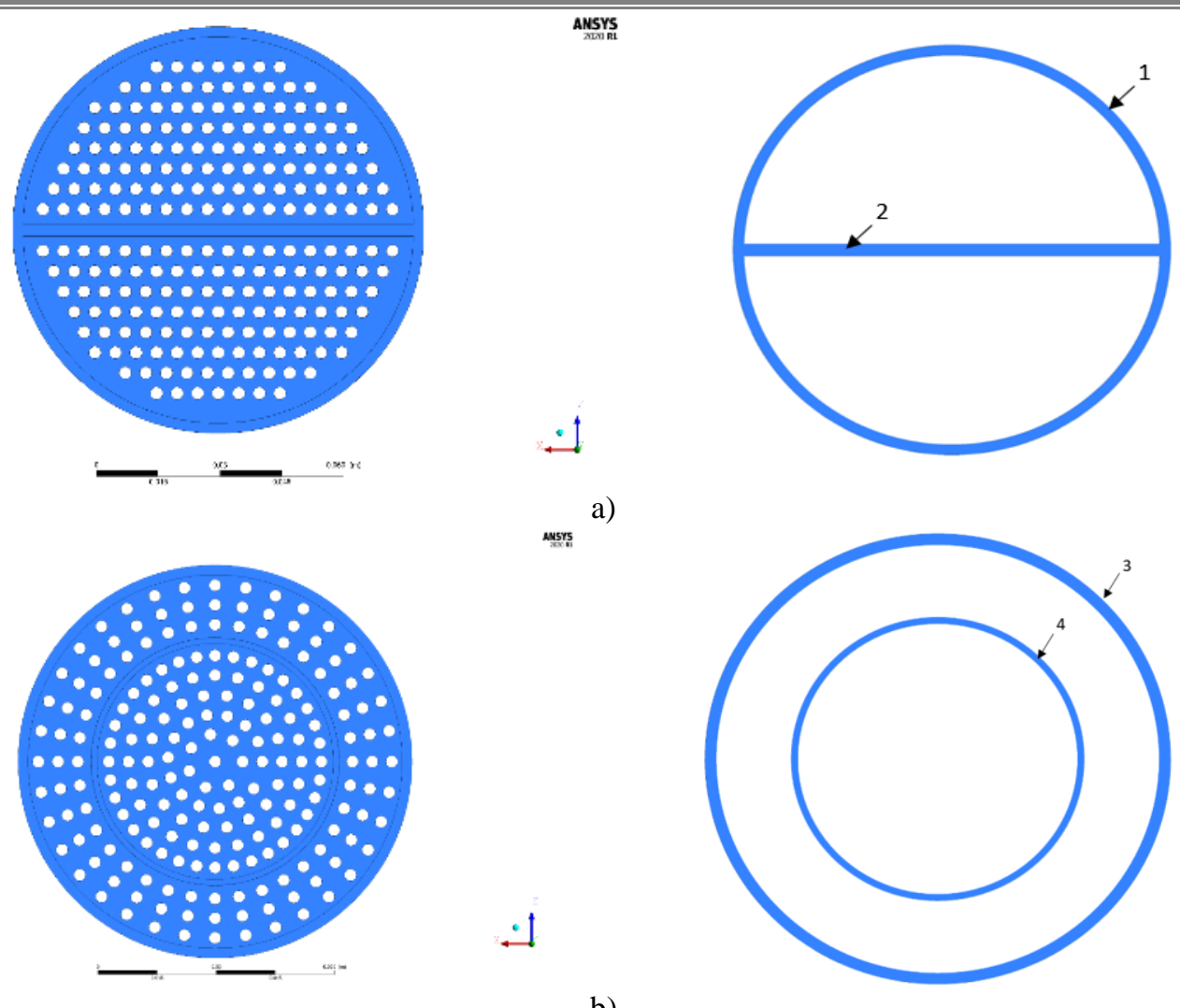

Figure 3. Arrangement of the spacer ring(s) for the two gas flows

After iterative simulations, it was found that the arrangement in triangles ensures a higher heat transfer coefficient than the arrangement in squares. Nevertheless, the overall pressure drop is higher in this case. Having in view, that the main objective is to have a higher transversal heat transfer, at the level of the active plate, the arrangement in the triangle has been further studied.
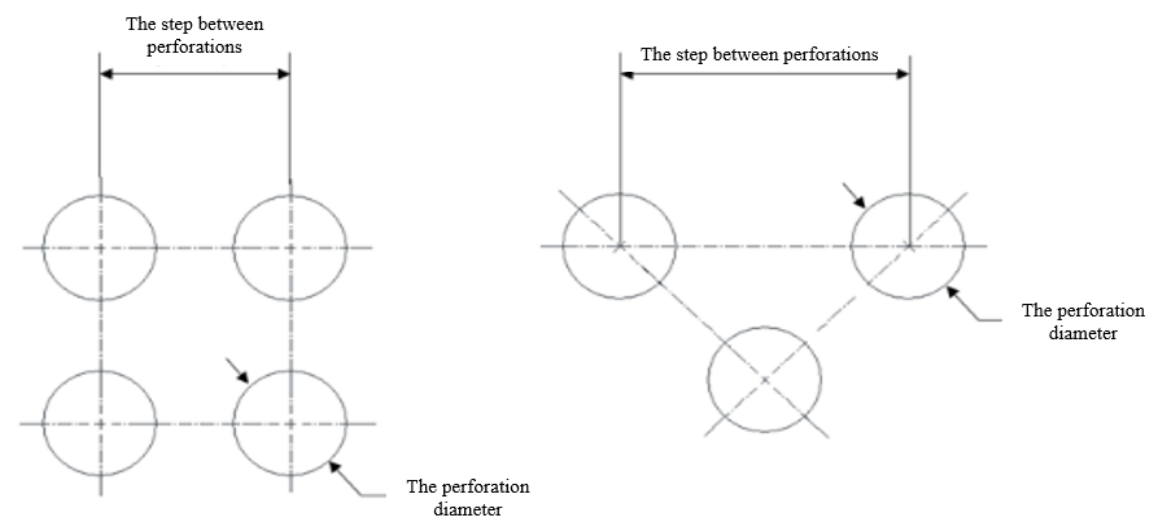

Figure 4. Active plate holes arrangement for the first solution 
The temperature distributions, for both solutions, after ANSYS iterative computation are presented in Figure 5. This preliminary analysis has been used the following input data: hydrogen mass flow $=0.0008 \mathrm{~kg} / \mathrm{s}$, helium mass flow $=0.001 \mathrm{~kg} / \mathrm{s}$, inlet hydrogen temperature $\mathrm{T}_{\mathrm{H} 2}=300 \mathrm{~K}$, inlet helium temperature $\mathrm{T}_{\mathrm{He}}=80 \mathrm{~K}$, working pressure for both gas flows were $2 \mathrm{MPa}$. The results showed that the spacers arranged circularly and concentrically offer an increase of the cooling of the hot gas flow by about $20 \%$ compared to the other solution. Both gas flows have been in the laminar regime, Reynolds number being 345 for helium and 460 for hydrogen. Several simulations were done, but with the increasing of the Reynolds number, in the laminar regime range, severe pressure drops have obtained corroborated with lower heat transfer in the active plates.

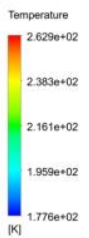

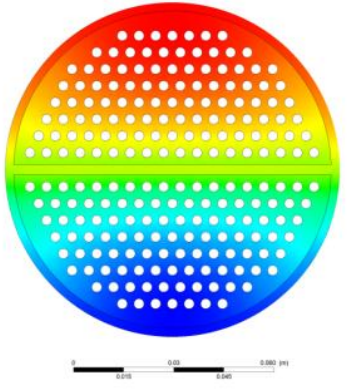

a)

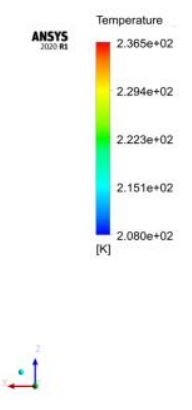

Figure 5. Temperature distribution $[\mathrm{K}]$ in the $\mathrm{MHE}$

\subsection{The active plate height effect on heat transfer quality and pressure loss}

The next analysis has been made to determine the influence of the height of the active plate.

The numerical data (Figure 6) proved that increasing the height of the copper plate will lead to an increase in the convective heat exchange surface, through the height of the flow channel. This increase of the active convective surface leads to an improvement of the conductive heat transfer in the active plates, but this will come with an important increase in the weight of the equipment and with higher pressure losses of the working fluids.
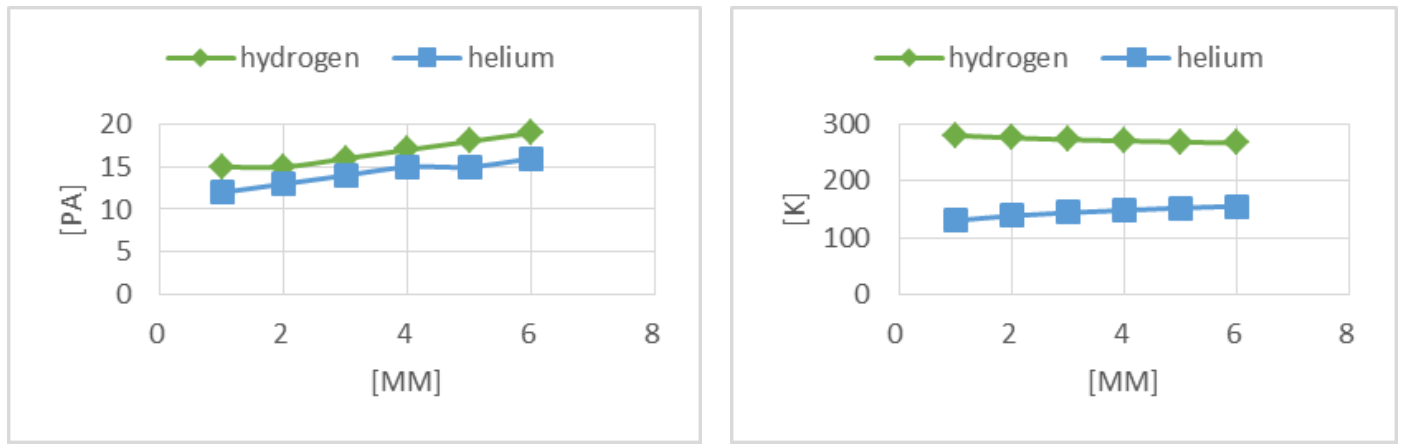

Figure 6. The plate height effect on heat transfer quality and pressure loss

Therefore, to have a balance between the quality of the heat transfer, the pressure losses, and the weight of the heat exchanger, the height of the copper plate has been chosen to be $4 \mathrm{~mm}$. 


\subsection{The spacer ring height effect on heat transfer quality and pressure loss}

The spacer rings which are made of stainless steel, due to their low thermal conductivity coefficient, will act as a barrier and will prevent the transfer of conductive heat in between the active plates, minimalize the axial heat losses. Obviously that the main function of the spacer rings is to separate the counter-current gas flows. The analyzes performed for small variations of their height, (Figure 7), shows that the thinner it is in relation to the active plate, the heat transfer is increased and pressure losses are reduced.
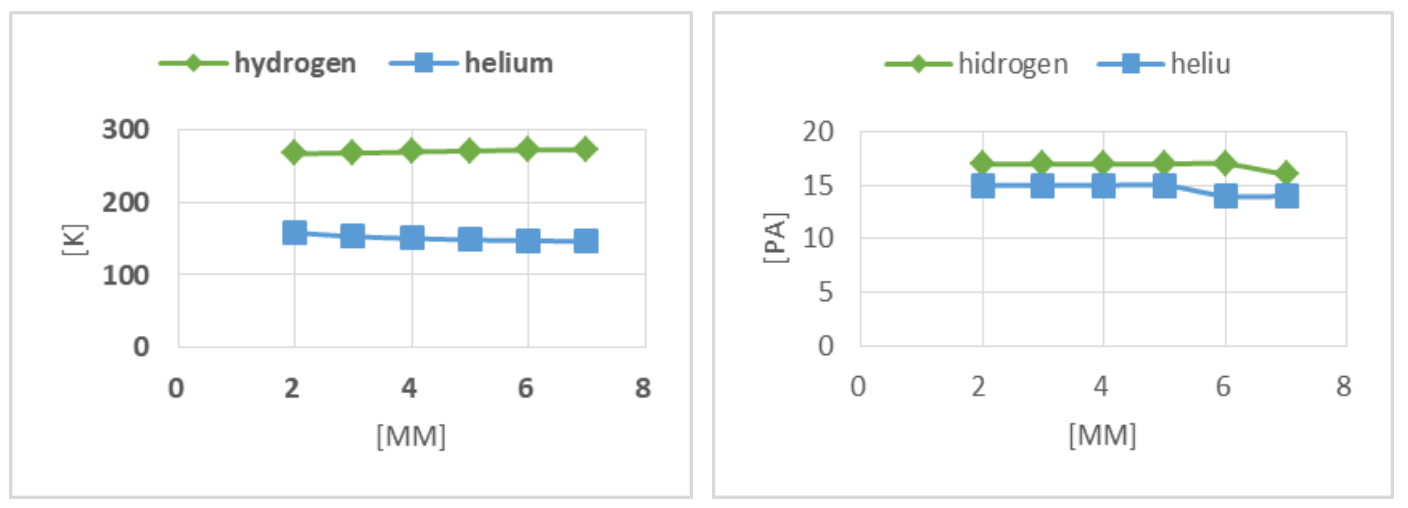

Figure 7. The spacer rings height effect on heat transfer quality and pressure loss

In all the simulations made, the spacer rings do not introduce additional pressure losses, other than those established by the flows through the holes of the active plates. Increasing the height of the spacer rings conduct to an increase in the distance between two active plates and thus the gas flow deflects in the space between the two active plates and appears to a decrease in the tunnelling gas flow through the holes from the active plates. Higher spacer rings with 6-8 $\mathrm{mm}$ height, offer the possibility to weld the spacer rings to the active plates, but in this study, the optimal spacer height determined was $3 \mathrm{~mm}$.

\subsection{The effect of the active plates holes diameter and distribution on heat transfer quality and pressure loss}

In (Farhani et al., 2005; Babulal et al., 2015) has been shown that the diameter and the distribution of the active plate holes at their surface play an important role. Different models were analysed to evaluate the effects of the arrangement and diameters of the holes form the active plates and the simulations were done modifying the geometric parameters of the holes their distribution in the active plates and the gas flows. The results showed that the temperature variation can be kept in a limited range but the pressure losses increase with the increasing of the inlet speed of gases. For the configurations with the smallest holes, a high value of the friction coefficients between the gas and the walls is indicated, the gases being sensitive to the change of the geometry of the flow path. Two important conclusions were obtained from the analyzed models, respectively that a small difference between the diameters of the holes for the counter-current gas flows and a larger diameter on the helium side will lead to smaller pressure losses. Moreover, the lower the length/diameter ratio is, the thermal and hydrodynamic boundary layers are broken before they are developed completely. 


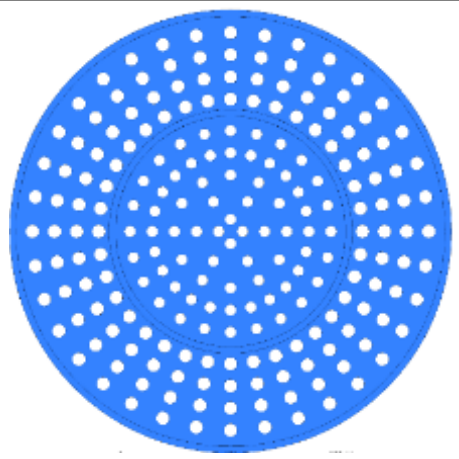

Figure 8. Perforations (holes) diameters $\mathrm{He}=3 \mathrm{~mm}, \mathrm{H}_{2}=2.5 \mathrm{~mm}$

For the chosen model of active plate (Figure 8) were performed small reconfigurations of the diameters of the holes in order to increase the velocity of fluids in a certain range, and thus obtaining an increase of both Reynolds and Nusselt numbers and with this, increase the convective heat transfer coefficient to the active plates. The number of holes of the active plates was evaluated because a higher number reduces the unperforated surface, which, in fact, will transmit the thermal load, and therefore, in the studied model, $85 \%$ of the active plate is the unperforated zone.

\section{SIMULATION PARAMETERS}

Matrix heat exchangers will incorporate, depending on their efficiency, a large number of plates in the stacked matrix, determined by the requested design parameters. In the studied matrix heat exchanger, the copper active plates have $110 \mathrm{~mm}$ diameter with uniform tubular perforations for each flux. The size of the holes for the warm flux is 2.5 $\mathrm{mm}$ respectively $3 \mathrm{~mm}$ for the cold flow. The other geometrical characteristics are provided in the Table 1.

Table 1. Geometrical characteristics for equipment components

\begin{tabular}{|c|c|c|c|}
\hline Component & Material & $\begin{array}{c}\text { Diameter } \\
{[\mathbf{m m}]}\end{array}$ & $\begin{array}{c}\text { Height } \\
{[\mathbf{m m}]}\end{array}$ \\
\hline Plate & copper & 110 & 4 \\
\hline Spacer & stainless steel & $110 / 107,65 / 62$ & 3 \\
\hline Sealing head & stainless steel & $110 / 107,65 / 62$ & 10 \\
\hline
\end{tabular}

The availability of thin plates with uniformly aligned tubular holes gives a high length-to-diameter ratio of 1.33 and 1.6, respectively, which ensures high efficiency, coupled with good structural integrity for the current application. The holes were positioned on concentric circles, spaced $5 \mathrm{~mm}$ and $6 \mathrm{~mm}$ apart, respectively, so as to occupy about $15 \%$ of the total non-perforated unit area initially considered.

All the holes from the active plates, from each side of the gas inlet, were provided with chamfers with $\mathrm{R}=0.2 \mathrm{~mm}$. After all the presented evaluations, the proposed model of a matrix heat exchanger has five pairs of plate-spacer and two covers (Figure 9). 


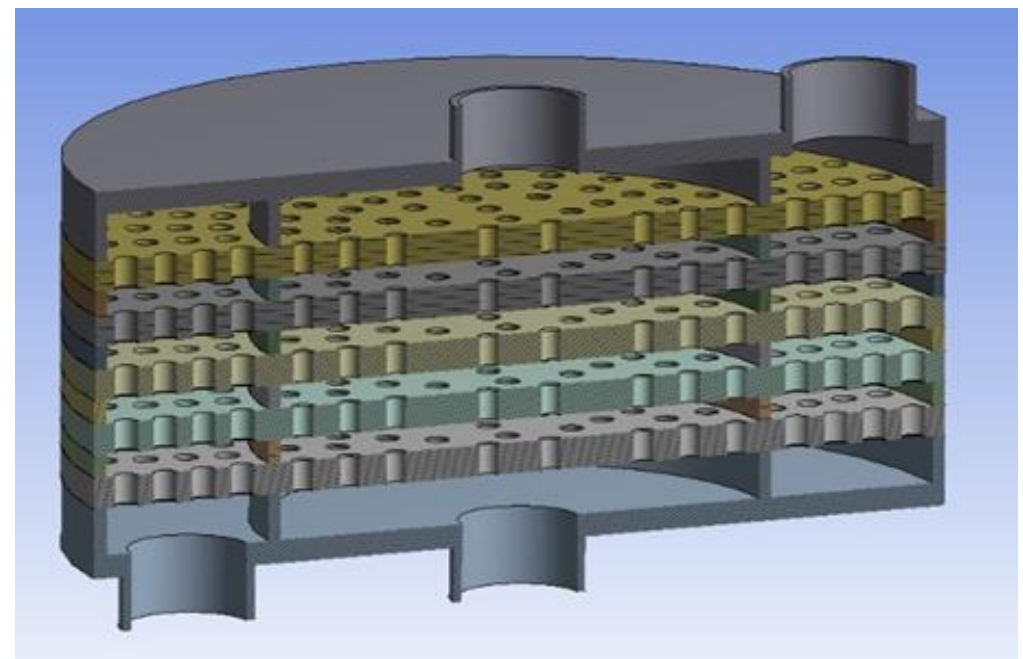

Figure 9. Cross section of the proposed MHE from ANSYS Design

The volume occupied by each of the system components from the matrix heat exchange model are displayed in Table 2.

Table 2. The volumes occupied by the system components

\begin{tabular}{|c|c|}
\hline & Volume $\left[\mathbf{m}^{\mathbf{3}}\right]$ \\
\hline $\mathrm{H}_{2}$ & $8,28 \cdot 10^{-5}$ \\
\hline $\mathrm{He}$ & $1,6 \cdot 10^{-4}$ \\
\hline Plates & $1,62 \cdot 10^{-4}$ \\
\hline Spacers, sealing heads & $7,57 \cdot 10^{-5}$ \\
\hline
\end{tabular}

The model was meshed with ANSYS Meshing module with more than 2,7 million knots and 13,5 million elements. The built-in default settings were given by the order of the elements as linear, individual size equal to $2 \mathrm{~mm}$. High grid densities have been used in all areas because high-temperature gradients occur. Considering that the quality of mesh plays a significant role in the accuracy and stability of numerical calculation, the mesh was done according to the suggested quality indicators of ANSYS Meshing, listed below in Table 3 .

Table 3. ANSYS Meshing quality indicators

\begin{tabular}{|c|c|c|}
\hline Quality indicator & Result via ANSYS Meshing & Reference range \\
\hline Element quality & 0,837 & 0 (low) $\longrightarrow 1$ (perfect) \\
\hline Aspect ratio & 1,850 & 1 (perfect) $\longrightarrow \infty$ (low) \\
\hline The Jacobian Report & 1 & 1 (perfect) $\longrightarrow \infty($ low $)$ \\
\hline Asymmetry & 0,228 & $\begin{array}{l}0-0,25 \text { excellent } / 0,25-0,50 \text { very } \\
\text { good } / 0,50-0,80 \text { good } / 0,80- \\
0,94 \text { acceptable } / 0,95-0,97 \text { bad } \\
/ 0,98-1,00 \text { unacceptable }\end{array}$ \\
\hline Orthogonal quality & 0,770 & $\begin{array}{l}0-0,001 \text { unacceptable } / 0,001- \\
0,14 \text { bad / } 0,15-0,20 \text { acceptable } \\
/ 0,20-0,69 \text { good } / 0,70-0,95 \\
\text { very good } / 0,95-1,00 \text { excellent }\end{array}$ \\
\hline
\end{tabular}


The simulation parameters, presented in Table 4, were chosen so as to be closer to the real working conditions of a matrix heat exchanger.

Table 4. Simulation parameters

\begin{tabular}{|c|c|}
\hline Simulation parameters & Value \\
\hline $\mathrm{T}_{\text {hydrogen, } \mathrm{i}}, \mathrm{K}$ & 300 \\
\hline $\mathrm{T}_{\text {helium, } \mathrm{i}}, \mathrm{K}$ & 90 \\
\hline $\mathrm{m}_{\text {hydrogen }}, \mathrm{kg} / \mathrm{s}$ & 0,0008 \\
\hline $\mathrm{m}_{\text {helium }}, \mathrm{kg} / \mathrm{s}$ & 0,001 \\
\hline $\mathrm{P}_{\text {hydrogen }}, \mathrm{MPa}$ & 0,2 \\
\hline $\mathrm{P}_{\text {helium }}, \mathrm{MPa}$ & 0,2 \\
\hline
\end{tabular}

\section{RESULTS}

The results obtained for $52 \mathrm{~mm}$ in height of the matrix heat exchanger model proposed are shown in Table 5. The most important result is that from the simulation performed, for the proposed model, was obtained a $61.6 \mathrm{~K}$ difference between the inlet temperature and the outlet temperature of the hydrogen gas flow and with very small pressure losses, between 0.0003 to $0.0004 \mathrm{MPa}$. The pressure decreases monotonically along the heat exchanger in both fluid zones as desired.

Table 5. Simulation results

\begin{tabular}{|c|c|c|c|c|c|c|c|c|}
\hline & \multicolumn{2}{|c|}{ Pressure [MPa] } & \multicolumn{2}{c|}{ Temperature [K] } & \multicolumn{2}{c|}{ Flow [kg/s] } & \multicolumn{2}{c|}{ Velocity [m/s] } \\
\hline & inlet & outlet & inlet & outlet & inlet & outlet & inlet & outlet \\
\hline $\mathrm{H}_{2}$ & 0.1998 & 0.1994 & 300 & 238.47 & 0.0008 & -0.00079 & 55.82 & 56.49 \\
\hline $\mathrm{He}$ & 0.1998 & 0.1995 & 90 & 226.39 & 0.001 & -0.001 & 35.23 & 36.85 \\
\hline
\end{tabular}

In addition to the above, the velocity profile for gas flow zones (Figure 10 and Figure 11) shows its dependence on the way in which the holes are arranged on the plate, respectively their distribution on the active plates surfaces.
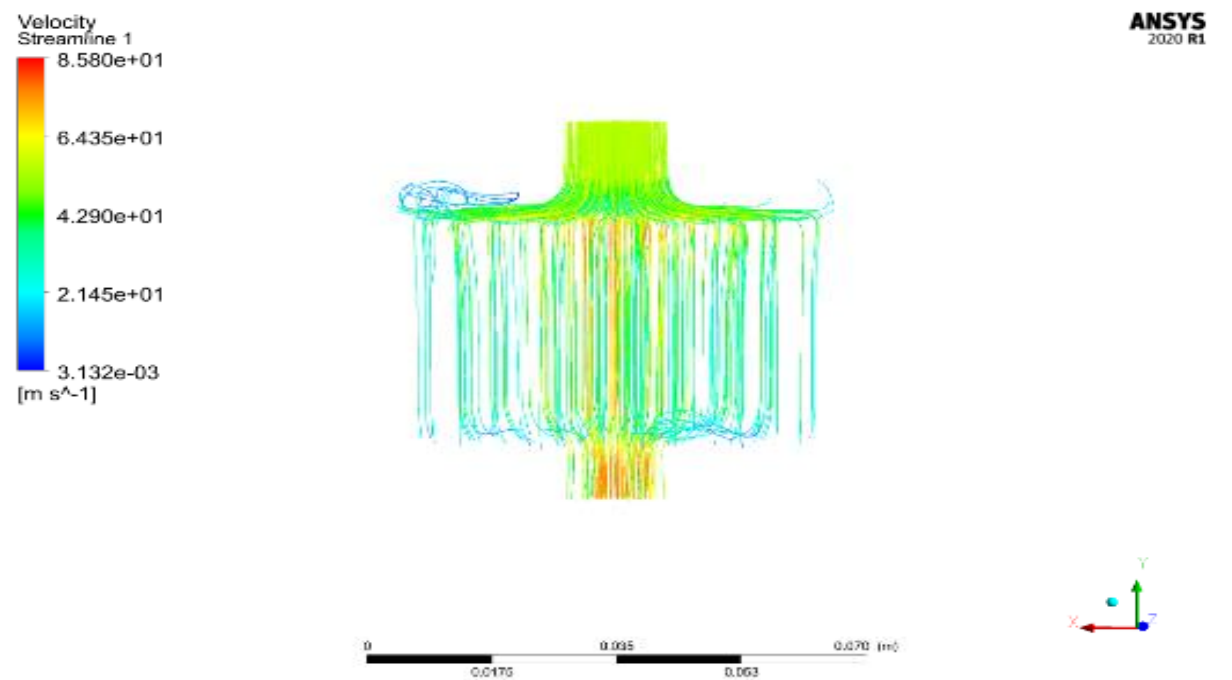

Figure 10. Velocity profile for hydrogen chamber 

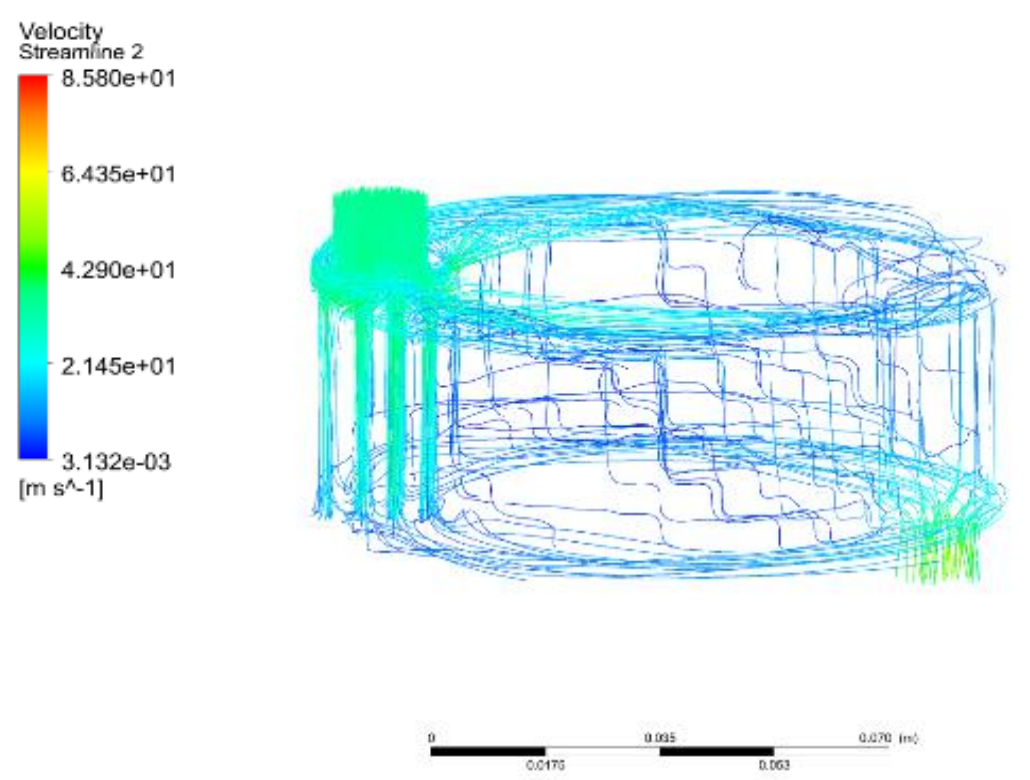

ANSYS

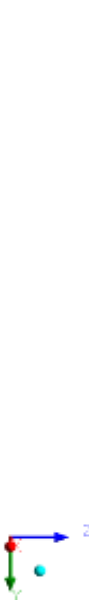

Figure 11. Velocity profile for helium chamber

\section{CONCLUSIONS}

In a cascade of distillation columns, the mixture to be separated is transferred between the columns either by pressure differences or, most often with metal bellow pumps, with low flow and pressure up to $0.1 \mathrm{MPa}$. Due to the fact that the transfer pumps operate at ambient temperature, the temperature of the gas transferred between two columns must be lowered to a value as close as possible to the working temperature in the column. Heat exchangers functioning at very low pressure are not efficient for this process, therefore a conceptual model of a matrix heat exchanger has been analysed, in order to obtain the largest temperature drop correlated with the lowest pressure losses, in a laminar flow regime. A multitude of geometric shapes of the holes from the thermally active plates were analysed, starting from their diameters and lengths, their forms, conical or stepped shapes, to the analysis of the influence of the chamfers of these holes (dimensions, angles, etc.) and to the influence of the distribution of the holes on the surfaces of the thermally active plates. Influences of the geometric parameters mentioned have been studied in close correlation with the variation of the pressures and mass flows of the studied gases, maintained the flow regimes in the laminar flow range. Best results were obtained for active plates with $110 \mathrm{~mm}$ diameter and $4 \mathrm{~mm}$ thickness. The diameters of the holes from the active plates were $3 \mathrm{~mm}$ for the helium gas stream and $2.5 \mathrm{~mm}$ for the hydrogen gas stream. The holes from active plates from the helium gas flow side have been reconfigured, in order to reduce the pressure losses and the active plates are without holes in the proportion of $85 \%$ because the unperforated surface transmits the thermal load. The ratio between the length (thickness of the plate) and its diameter of the holes of the active plates was in the range of 0.3 - 4.0, also mentioned by Venkatarathnam G. et al, 1990.

The next activity will be to manufacture a prototype with the same geometrical characteristics and testing in the same conditions from ANSYS simulations. Based on the experimental results, a design model of a matrix heat exchanger will be proposed. 


\section{PRELIMINARY DEVELOPMENT OF A CONCEPTUAL MODEL OF MATRIX HEAT EXCHANGER}

Acknowledgements: The work was supported by the Romanian Ministry of Research and Innovation - grants number: PN19 110102 "Development of methods for testing materials used in the field of cryogenics and cryogenic technological systems for isotopic purification and separation"

Funding: Project PN 191101 02, Contract no. 9N/2019 (10/2020), financed by the Ministry of Education and Research, Romania.

Author contributions: C. Bogdan wrote the paper with input from all authors, C. Bogdan, C. Brill and A. Lazar designed the model, C. Bogdan performed the analytic calculations and performed the numerical simulations, O. Sirosh and M. Vijulie contributed to the analysis of the results.

Conflict of Interest Statement: The authors declare no conflicts of interest associated with this manuscript.

\section{REFERENCES}

Venkatarathnam G., Sarangi S., (1990). Matrix heat exchangers and their application in cryogenic system", Cryogenics, , 30(11), 907-918

Farhani F., Sarangi S., (2005). Analysis of matrix heat exchanger of circular geometry, Proceedings of the International Conference on Mechanical Engineering, (ICME2005) 28-30 December 2005, Dhaka, Bangladesh

Ragab M. Moheisen, Transport phenomena in fluid dynamics: matrix heat exchanger and their applications in energy systems, Applied Research Associates, July, 2009

Dilevskaya E.V., Cryogenic Micro-Heat Exchangers, Mashinostroenie, Moscova, 1978

Ornatsakii A.P., (1983). Experimental study of perforated plate heat exchanger for micro cryogenic systems, Promish Teplo Tekhn 28-33

McMahon H.O., Bowen R.J., Bleyle Jr.G.A., (1950). A perforated plate heat exchanger, Trans ASME, 72, 623-632

Eckert E.R.G., Drake Jr. R.M., (1974). Heat and Mass Transfer, Tata McGraw Hill, New Delhi, India

Fleming R.B., (1969). A compact perforated plate heat exchanger, Adv Cryo Eng., 197-204

Mikulin E.I., et. al., (1979). Efficiency of perforated plate array heat exchangers, transl: Chem Petr Eng., 351-355

Mikulin E.I., et. al., (1980). Study of matrix-type heat exchangers made of perforated plates", transl: Chem Petr Eng., 514-519

Fleming R.B., (1969). Heat exchanger of porous metal, US Patent 3433299

Hubbell R., Cain C.L., (1986). New heat transfer and friction factor design data for perforated heat exchangers, Adv COo Eng., 31, 383-390

Shevyakova S.A., Orlov V.K., (1983). Study of hydraulic resistance and heat transfer in perforatedplate heat exchangers, transl: J. Eng. Phys., 734-737

Babulal P.V., Bora N.V., (2015). A review on highly compact perforated plate heat exchanger for cryogenic applications, (INCRRET-2015), International Journal of Advance Engineering and Research Development - IJAERD 